
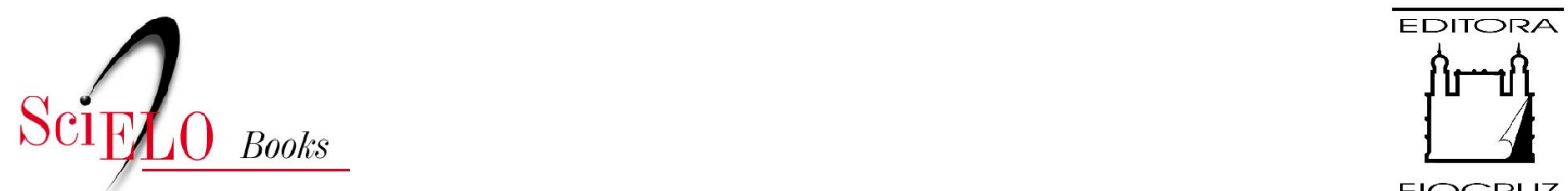

FIOCRUZ

\title{
Análise quantitativa da tradução para o português de expressões idiomáticas nas legendas de fãs do seriado Glee
}

\author{
Nathalia Leite de Queiroz Sátiro \\ Sinara de Oliveira Branco
}

\section{SciELO Books / SciELO Livros / SciELO Libros}

SÁTIRO, N. L. Q., and BRANCO, S. O. Análise quantitativa da tradução para o português de expressões idiomáticas nas legendas de fãs do seriado Glee. In: SOUZA, F. M., and ARANHA, S. D. G., orgs. Interculturalidade, linguagens e formação de professores [online]. Campina Grande:

EDUEPB, 2016, pp. 103-143. Ensino e aprendizagem collection, vol. 2. ISBN 978-85-7879-347-0. Available from: doi: $10.7476 / 9788578793470.0007$. Also available in ePUB from: http://books.scielo.org/id/qbsd6/epub/souza-9788578793470.epub.

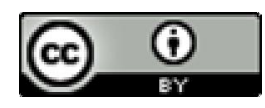

All the contents of this work, except where otherwise noted, is licensed under a Creative Commons Attribution $\underline{4.0 \text { International license. }}$

Todo o conteúdo deste trabalho, exceto quando houver ressalva, é publicado sob a licença Creative Commons Atribição 4.0.

Todo el contenido de esta obra, excepto donde se indique lo contrario, está bajo licencia de la licencia $\underline{\text { Creative }}$ Commons Reconocimento 4.0 . 


\title{
ANÁLISE QUANTITATIVA DA TRADUÇÃO PARA O PORTUGUÊS DE EXPRESSÕES IDIOMÁTICAS NAS LEGENDAS DE FÃS DO SERIADO GLEE
}

\author{
Nathalia Leite de Queiroz Sátiro (UFCG/UEPB) \\ Sinara de Oliveira Branco (UFCG)
}

\begin{abstract}
A legendagem de fãs tem ganhado visibilidade no Brasil, pois quem é fã de séries não quer aguardar os canais de TV a cabo disponibilizarem os episódios com legendas em português ou dublados, uma vez que esse processo pode levar dias. Por essa razão, os fãs das séries que têm conhecimento da língua inglesa traduzem, informalmente, as legendas dos seriados que eles acompanham. As legendas produzidas por fãs se popularizaram rapidamente no Brasil, pois elas são disponibilizadas até mesmo no dia seguinte ao lançamento do episódio nos Estados Unidos. Verificamos a grande popularidade das legendas de fãs em sites, como por exemplo, o Legendas $\mathrm{TV}^{1}$, em que o seriado The Walking Dead ${ }^{2}$ bate recordes de legendas mais baixadas a cada episódio. Por esse contexto, consideramos necessário analisar a legenda de fãs, pois cada vez mais, os grupos de tradutores de legendas
\end{abstract}

1 O site Legendas TV disponibiliza as legendas de filmes e seriados feitos por grupos de legendagem de fãs.

2 Mais de cem mil fãs baixam as legendas de cada episódio do seriado norte-americano The Walking Dead. 
se organizam e criam suas próprias regras dentro da legendagem de fãs.

A atividade de legendagem é técnica e específica, tendo que se respeitar limites de caracteres por segundo, o tempo de exposição de legendas em tela, a cultura da língua de origem e de chegada, entre outros aspectos, o que pode fazer com que o tradutor de legendas precise sintetizar, adaptar o que foi dito, omitir algumas falas, para que haja tempo de leitura. As nuances do ato tradutório na produção de legendas chamou a atenção e nos fez perceber que um dos aspectos relevantes na série selecionada diz respeito às traduções de expressões idiomáticas (doravante EI).

Acreditamos que a atividade de tradução de legendas de seriados de TV é um tema que necessita de abordagem investigativa adicional, que venha a observar o resultado do trabalho tradutório de tais legendas para que possamos verificar as implicações dessas traduções na cultura brasileira, além de servir como material para cursos de tradução e insumo para pesquisa.

Pretendemos, portanto, analisar a tradução de EI em legendas de três episódios do seriado Glee, da língua inglesa norte-americana para a língua portuguesa do Brasil, produzida por uma equipe de tradutores de legendas de fãs.

Para tanto, buscamos: identificar, categorizar e quantificar as estratégias tradutórias utilizadas para a tradução de EI nas legendas. Para desenvolver este estudo, os dados foram coletados, seguindo os passos: i) seleção de legendas produzidas por uma equipe de legendagem 
de fãs ${ }^{3}$ nos episódios escolhidos e; ii) análise quantitativa das legendas feitas por fãs, com o intuito de investigar as traduções de EI.

O arcabouço teórico aqui utilizado está baseado na Tradução Audiovisual; na Legendagem; na Semiótica e Semiótica da Legendagem; nas Expressões Idiomáticas e; nas Estratégias de Tradução. Acreditamos que esta investigação poderá ajudar não apenas pesquisadores da área de tradução, como também os produtores de legendas, uma vez que é comum tradutores se depararem com EI nos textos que eles traduzem. Além disso, este capítulo pode ajudar aprendizes e professores de línguas a observarem o uso da língua através do meio audiovisual, justificando a importância desta investigação.

\section{O texto em legenda}

Daremos início a este capítulo tratando da tradução audiovisual (TAV), um campo específico nos Estudos da Tradução, no qual a legendagem está inserida. Em termos históricos, Silva (2009) afirma que a questão de

3 A equipe de legendagem de fãs aqui mencionada é a Griots Team, que é uma das equipes que se organizam para legendar filmes e seriados. As pessoas que fazem parte da equipe não são remuneradas. Os tradutores de legendas participam de treinamento antes de entrarem para a equipe. A organização da equipe e do trabalho acontece da seguinte maneira: cada episódio de seriado ou filme a ser traduzido é dividido entre cerca de seis tradutores de legendas (o número varia de acordo com a quantidade de linhas a serem traduzidas) e um ou dois revisores que padronizam os termos e corrigem os erros encontrados. Os tradutores de legendas mais experientes acabam se tornando revisores. 
combinação de sons e imagens gravados é quase tão antiga quanto o cinema. Segundo Silva (2009), a primeira exibição do cinema foi em 1895, na França, e foi a partir daí que o cinema se expandiu por toda a Europa, depois pelos Estados Unidos e pelo restante do mundo. A TAV surgiu diante dessa globalização e da necessidade de o mundo se relacionar e mostrar as diferentes culturas.

A autora divide os tipos de tradução audiovisual em: 1) dublagem, na qual nada nas imagens é alterado e se substitui o áudio original por um áudio na língua de chegada; 2) voice-over, em que o áudio original não é apagado e outro áudio na língua diferente é sobreposto; 3) legendagem, quando se utiliza um texto escrito, transmitido simultaneamente à fala; e 4) closed-captions ${ }^{4}$, que dá acessibilidade a deficientes auditivos, pois é direcionada a esse público.

Os estudos da TAV ganham destaque nos anos 2000 com Díaz Cintas e Anderman (2009) que descrevem os tipos de TAV e o seu crescimento nos últimos anos, ressaltando que um dos aspectos positivos é o acesso de pessoas com alguma deficiência auditiva ou visual aos meios audiovisuais. Os tipos de TAV, segundo os autores, são: 1) a dublagem, cuja principal meta é a sincronia entre os lábios do ator original e a voz do dublador; 2) a audiodescrição, que é a descrição gravada em voz alta e integrada ao áudio do vídeo, geralmente usada para ajudar deficientes

4 Closed-captions é uma das modalidades da TAV que faz a inclusão dos deficientes auditivos. Para a autora, os closed-captions são um tipo de legendagem e "não apenas ocorre na tradução, mas também na língua nativa, focando seu público nos portadores de algum grau de deficiência auditiva" (SILVA, 2009, p.15). 
visuais na compreensão dos vídeos; 3) a narração, que consiste em um texto descritivo traduzido, lido por um narrador sem aparecer em cena; 4) no voice-over, ouve-se a voz original em volume mais baixo e o texto oral traduzido é sobreposto; e, 5) a legendagem, que é a transposição do discurso falado em forma de texto escrito, sendo o tipo de TAV mais popular, por ser mais econômico.

No entanto, para Franco e Araújo (2011), nem todos esses tipos de tradução são do meio audiovisual. Levando em consideração o contexto desse capítulo, concordamos com as autoras de que essa divisão de tipos de TAV é extensa e que, para uma melhor compreensão delas, esses tipos devem ser reduzidos em categorias. Para Franco e Araújo (2011), os tipos de TAV são: 1) legendagem, que se subdivide em três: legendagem para ouvintes, legendagem para surdos e ensurdecidos (LSE) e legendagem eletrônica (surtitling); 2) modos de revocalização: a dublagem e o voice-over; e 3) a audiodescrição (AD). Para as autoras, a narração e a interpretação não fazem parte da modalidade da TAV - e nós concordamos com elas.

Este capítulo se atém à legendagem que, conforme Araújo (2004) é a interpretação condensada ou não das falas de um filme, seriado ou outro programa de televisão-definição da qual partilhamos. No Brasil, antes de os canais de TV a cabo se popularizarem, a legendagem estava presente apenas nos cinemas e nos vídeos domésticos. Nos dias atuais, na TV a cabo, a incidência da legendagem é maior do que a da dublagem, o mesmo não ocorre na TV aberta, uma vez que se dá de maneira inversa.

A seguir, será detalhado não só o trabalho técnico de legendagem, mas também a sua função baseada em estudos analíticos de seu papel no cinema. 


\section{Legendagem}

$\mathrm{Na}$ tradução de legendas, existem diversos obstáculos a serem enfrentados pelos tradutores de legendas. Sobre isso temos a contribuição de Gorovitz (2006) afirmando que,

O tradutor, pelas limitações técnicas impostas, deve resumir e sintetizar ao máximo o diálogo, tentando produzir uma mensagem curta e clara e tendo unidade semântica. [...] A mensagem deve estar contida em, no máximo, duas linhas de até 56 caracteres. A posição da legenda, a fonte utilizada, a cor, o tempo de exposição, a escolha de palavras facilmente apreensíveis devem respeitar regras rígidas e, assim, limitam a liberdade do tradutor. Além disso, a projeção da legenda deve ser sincronizada à imagem: a tradução precisa aparecer e desaparecer conforme a sucessão do diálogo (GOROVITZ, 2006, p.65-66).

Ou seja, para produzir legendas, o tradutor deve compreender como funcionam os aspectos da legendagem e obedecer às regras que são impostas por ela. Podemos citar como exemplo dessas regras o limite de caracteres por linha, o número máximo de linhas, o tempo em que a legenda deve aparecer em tela. Cada empresa de 
legendagem tem as suas próprias regras e manuais, que diferem das regras mencionadas por Gorovitz (2006).

Além disso, há também uma grande quantidade de elementos da oralidade que são intransponíveis no discurso escrito, por isso, é preciso destacar que a legendagem "incorpora certos traços, mas rejeita outros por querer se aperfeiçoar ao discurso oral" (RIDD, 1995, p.478). Por causa da passagem do oral para o escrito perdem-se muitas informações, pois elas, muitas vezes, não podem estar nas legendas, devido às limitações técnicas. Então, faz-se necessário omitir, mas, para isso, o tradutor de legendas tem que conhecer bem o produto, seja ele um filme, um seriado, ou outro meio audiovisual, para que saiba em que momentos se pode fazer os cortes.

Linde e Kay (2009) discutem sobre esse tema e sugerem que o tradutor de legendas avalie a relevância de cada segmento das mensagens, para que, em caso de falta de espaço na legenda, seja possível omitir informações que não causarão perdas importantes no contexto. Os autores abordam ainda alguns elementos de fala que podem parecer que não são importantes e são facilmente omitidos em legendas, como: "actually, well, you know, etc.". No entanto, se eles forem a marca de fala de algum personagem, devem ser respeitados para que não o descaracterize. Portanto, o texto da legenda é geralmente uma parte condensada do texto falado no vídeo, devido às limitações de tempo e de espaço e da velocidade de leitura do espectador. É importante também, respeitar a sincronia do áudio com a legenda, para que o leitor não leia novamente a mesma legenda uma vez concluído o áudio. Por isso, vemos o quanto é importante pensar no leitor das legendas, respeitando os aspectos citados, já que 
as legendas podem mudar o ritmo de leitura de quem as acompanha.

O foco deste capítulo é a legendagem de fãs que, em conceito, é igual à legendagem profissional, pois os tradutores de legenda também seguem regras e técnicas. Um dos aspectos que as difere é o tipo de tradutor de legendas: aquele que faz o trabalho de legendagem como profissão; e o fã que faz por hobby, assumindo uma função social. Esse papel social que o tradutor de legendas de fãs assume faz com que pessoas sem TV a cabo ou cinema próximo ao local onde vivem tenham acesso a filmes e seriados. Além disso, Carvalho (2005) assevera que, na legendagem profissional, o tradutor de legendas, na maioria dos casos, traduz a legenda apenas com base no roteiro do filme ou do seriado, não tendo acesso às imagens e ao áudio, pois as empresas podem não liberar o material com receio da pirataria. Então, podemos observar que há uma vantagem na legendagem de fãs, uma vez que o tradutor de legendas tem acesso ao vídeo e, diversas vezes, tem também acesso a uma legenda já com os tempos inclusos ou um roteiro na língua original para traduzir. Carvalho (2005) afirma ainda que, na legendagem profissional, existem diferentes profissionais envolvidos, como: os funcionários que acompanham os diálogos do roteiro do vídeo juntamente com o vídeo para indicar onde cada trecho de fala começa e termina; os tradutores, que recebem o roteiro e poucas vezes o material audiovisual e traduzem as falas em um software específico; os profissionais que ajustam a sincronia das legendas com o vídeo; os que fazem a inserção das legendas nas películas; e, por fim, a distribuidora que analisa o produto e o distribui. 
Na legendagem de fãs, normalmente, há o tradutor de legendas e o revisor. O primeiro, em posse do material audiovisual, produz a legenda utilizando um software ${ }^{5}$ específico, e ele mesmo pode fazer a sincronia das legendas com as falas; o revisor padroniza os termos, observa se as questões técnicas foram respeitadas e faz os ajustes necessários nelas e nas traduções. Vale salientar que a equipe de legendagem de fãs que produziu as legendas aqui analisadas não insere as legendas aos vídeos, ou seja, ela não pirateia o vídeo (distribuindo-o na internet), ela apenas publica a legenda feita ${ }^{6}$. Acreditamos que a legendagem de fãs seja um meio alternativo para que as pessoas tenham acesso a filmes e seriados.

Acerca do processo de legendagem no Brasil, conforme esboçado por Araújo (2004), observa-se que as pesquisas nessa área começaram a surgir na década de 1990. Quanto à classificação das legendas, elas podem ser classificadas segundo dois parâmetros: 1) o linguístico, que se subdivide em dois: a) intralingual, a legendagem na mesma língua do texto falado, e b) interlingual, a tradução dos diálogos de um filme ou programa de TV em língua estrangeira, por exemplo; e 2) o técnico, em que as legendas se subdividem em duas: a) abertas, as que são

5 O software utilizado pela equipe Griots Team é o Subtitle Workshop que será apresentado na medotologia deste trabalho.

6 Todo conteúdo produzido pela Griots Team está sob a licença Creative Commons Atribuição, Não Comercial, Compartilhamento Igual 4.0 (CC BY-NC-SA 4.0). A equipe não disponibiliza para download arquivos ou links de séries, filmes ou qualquer outro conteúdo protegido por direitos autorais. Outros detalhes acerca da equipe encontram-se no site: <http://www.griotsteam.com/>. 
sobrepostas à imagem antes da transmissão ou exibição e b) fechadas, closed-captions, cujo acesso ficará a critério do telespectador através de um decodificador de legenda localizado no controle remoto do aparelho de televisão (ARAÚJO, 2004).

As legendas aqui investigadas são legendas interlinguais, já que foram traduzidas do inglês para o português do Brasil e são abertas, pois elas, depois de produzidas, são inseridas ao vídeo pelo telespectador ou por alguém que conhece esses procedimentos. As legendas selecionadas são do seriado Glee feitas por uma equipe de fãs. Como o foco são as expressões idiomáticas produzidas a partir da fala dos personagens do seriado, direcionamos nossa análise para esse aspecto. Então, a seguir, apresentaremos conceitos importantes sobre EI que nos auxiliarão no momento de nossa análise.

\section{Expressões Idiomáticas em Contexto de Legendagem}

Ao estudar uma língua estrangeira ou ao visitar uma região e comunidade com costumes distintos dos nossos, percebemos as especificidades das expressões idiomáticas (EI), pois não há regra que as explique, seja com relação à sua formação ou ao novo sentido que as palavras juntas ganham. Além de conhecimento de léxico e da gramática de uma língua, temos que conhecer suas funções e seus sentidos, pois elas levam consigo aspectos culturais de cada lugar em que são usadas.

Para Tagnin (2005) uma EI é a expressão que não tem o seu significado transparente. Para a autora, o termo EI “englobará apenas expressões semanticamente convencionalizadas, istoé, cujo significado não pode ser depreendido 
a partir do significado de suas partes" (TAGNIN, 2005, p.64). A autora diferencia as EI de expressões convencionais, já que para ela, estas últimas possuem significado transparente. Quando as expressões deixam transparecer essa relação entre a imagem e o seu significado, Tagnin (2005) as classifica como expressões metafóricas. Para a autora, só seriam EI se essa relação de imagem aludida e significado não pudesse mais ser recuperada.

Baker (1992) discorre que as EI e expressões fixas são formas cristalizadas da língua que permitem pouca ou nenhuma variação, e no caso específico das EI, a autora destaca que elas carregam um significado que não pode ser compreendido por seus elementos individuais. Baker (1992) apresenta estratégias para a tradução de EI, tais como usar uma EI que tenha significado e forma similar; usar uma EI com significado similar, porém com forma diferente; parafrasear a EI; ou omitir a EI. Estas estratégias de tradução de EI propostas por Baker (1992) foram utilizadas para auxiliar na seleção do corpus, cuja explicação será apresentada no tópico seguinte.

Apresentamos, então, a definição sobre EI de Alvarez:

Uma expressão idiomática pode ser definida como uma unidade sintática e semântica. Ela forma uma estrutura sintagmática complexa que resulta numa unidade lexical conotativa e se refere a uma realidade específica com um sentido particular. $\mathrm{O}$ significado dela resultante independe do significado dos lexemas isolados que a compõem. Sua extensão de 
sentido é metafórica e o que mantém a unidade lexical é o todo significativo; são os lexemas gerando um novo sentido ao se combinarem que justifica a sua opacidade e o fato de serem indecomponíveis (ALVAREZ, 2011, p.123-124).

O que a autora quer dizer é que uma EI não deve ser compreendida pelo significado de cada um dos seus elementos, já que esses elementos juntos ganham um novo sentido.

A partir das definições discutidas acima e para atingir os objetivos desse capítulo, a definição de EI aqui utilizada será: uma estrutura sintagmática complexa, cujo sentido é compreendido através da unidade completa (e não dos lexemas isolados que a compõem) e do contexto cultural e geográfico. As EI podem ter sentido metafórico e em sua maioria não fazem sentido se tentarmos entender palavra por palavra isoladamente. Deve-se entender a combinação de palavras, pois ganharão um novo sentido ao se combinarem. As EI nem sempre serão indecomponíveis, uma vez que verificamos ser possível substituirmos uma palavra da EI e ela não perder o sentido idiomático, porém se quando essa substituição for feita a expressão perder o sentido idiomático, ela deixará de ser uma expressão idiomática.

Para nos auxiliar na análise das traduções das EI nas legendas, apresentaremos no subitem a seguir as estratégias de tradução propostas por Chesterman (1997). 


\section{Estratégias de tradução}

Segundo Chesterman (1997), os tradutores são pessoas especializadas em resolver certos problemas na comunicação. Para auxiliar os tradutores, o autor propõe estratégias de tradução nos níveis: sintático, semântico e pragmático.

As estratégias sintáticas são as que envolvem mudanças sintáticas, ou seja, elas manipulam as formas. As principais delas apresentadas por Chesterman (1997, p. 94-101) são: G1, Tradução literal (traduz-se o texto de chegada o mais próximo possível da estrutura gramatical do texto de partida); G2: Empréstimo, calque (se refere a uma escolha deliberada e não inconsciente); G3: Transposição (significa qualquer mudança de classe de palavra, por exemplo: de substantivo para verbo, de adjetivo para advérbio); G4: Deslocamento de unidade (ocorre quando uma unidade - morfema, palavra, frase, oração, sentença, parágrafo - do texto de partida é traduzida para uma unidade diferente no texto de chegada; G5: Mudança estrutural da frase (mudanças no nível da frase, incluindo número, exatidão e modificação na oração substantiva e na pessoa, número e tempo verbal); G6: Mudança estrutural da oração (tem a ver com a estrutura da oração em termos de suas frases constituintes); G7: Mudança estrutural de período (esta estratégia afeta a estrutura da unidade de sentença); G8: Mudança de coesão (é algo que afeta a referência intratextual, elipse, substituição, pronominalização e repetição, ou o uso de conectores e vários tipos); G9: Deslocamento de nível (em um deslocamento de nível - fonológico, morfológico, sintático e lexical-, o modo de expressão de um determinado item é modificado de um 
nível para outro); G10: Mudança de esquema (se refere aos tipos de mudanças que os tradutores incorporam na tradução de esquemas retóricos - paralelismo, repetição, aliteração, ritmo e métrica).

As estratégias semânticas, de acordo com Chesterman (1997, p.101-107), são as que manipulam os significados. São elas: S1: Sinonímia (não selecionam o equivalente óbvio, mas um sinônimo ou um termo quase sinônimo para evitar repetição por exemplo); S2: Antonímia (o tradutor seleciona um antônimo e combina com um elemento de negação); S3: Hiponímia (mudanças dentro das relações hiponímicas); S4: Conversões (são pares de estruturas verbais que expressam o mesmo sentido, porém com pontos de vistas controversos); S5: Mudança de abstração (uma seleção diferente do nível abstrato pode variar do abstrato para o mais concreto ou do concreto para o mais abstrato); S6: Mudança de distribuição (é a mudança de distribuição dos mesmos componentes semânticos para mais itens - expansão, ou para menos itens - compressão); S7: Mudança de ênfase (esta estratégia reduz ou altera a ênfase ou foco temático por uma razão ou outra); S8: Paráfrase (resulta em uma versão do texto de chegada que pode ser descrita como distante do texto de origem. componentes semânticos no nível lexical tendem a ser ignorados favorecendo o sentido pragmático de alguma outra unidade, como por exemplo: uma oração inteira); S9: Mudança de tropo (é a tradução de tropos retóricos, assim como a estratégia g10 aplicada à tradução de esquemas); S10: Outras mudanças semânticas (inclui outras modulações de vários tipos, como a mudança de sentido ou a direção de dêitica). 
Quanto às estratégias pragmáticas, Chesterman (1997, p.107-112) afirma que elas envolvem, geralmente, uma maior mudança do texto de partida e que podem incorporar mudanças sintáticas e/ou semânticas também. As estratégias pragmáticas são as que manipulam as mensagens propriamente ditas: Pr1: Filtro cultural (esta estratégia é também conhecida como naturalização, domesticação ou adaptação); Pr2: Mudança de explicitação (esta mudança é mais direcionada à informação explicita ou mais direcionada à informação implícita); Pr3: Mudança de informação (a adição de novas informações que são consideradas relevantes para o leitor do texto de chegada, porém não estão presentes no texto de partida, assim como omissão de informações); Pr4: Mudança interpessoal (esta estratégia altera o nível de formalidade, o grau de emotividade e envolvimento, o nível de léxico técnico, entre outros); Pr5: Mudança de elocução (as mudanças de elocução estão geralmente ligadas a outras estratégias, por exemplo: a mudança do modo verbal do indicativo para o imperativo (g5) também envolve uma mudança de elocução de afirmação para pedido); Pr6: Mudança de coerência (é a organização lógica da informação no texto, no nível ideacional); Pr7: Tradução parcial (este tipo de tradução abrange qualquer tipo de tradução parcial, como a tradução resumida, a transcrição, a tradução apenas dos sonhos, entre outras); Pr8: Mudança de visibilidade (diz respeito a mudança na presença de autoria ou a inclusão evidente ou em primeiro plano da presença tradutória, como as notas de rodapé, os comentários entre chaves ou os comentários adicionais explícitos); Pr9: Reedição (se refere à reedição, às vezes, radical que os tradutores precisam fazer em textos de partida mal escritos); 
Pr10: Outras mudanças pragmáticas (um dos exemplos seria mudança no layout do texto).

Após a exposição das estratégias com relação a estes três níveis sintático, semântico e pragmático, podemos dar como exemplos mais comuns: a questão da tradução literal estando no nível sintático, seguindo a forma gramatical do texto que está sendo traduzindo; a da paráfrase que se encontra no nível semântico, uma versão do texto de partida para o texto de chegada; e, o filtro cultural que está no nível pragmático, uma vez que se a frase a ser traduzida não fizer sentido para a língua de chegada, opta-se por fazer uma domesticação ou uma adaptação para o contexto da língua e da cultura do Brasil, no caso que estamos analisando.

Para contextualizar o que foi discutido, podemos ter como exemplos destes níveis e das estratégias de traduções citadas, as seguintes frases:

Quadro 1 - Trecho retirado do primeiro episódio da quinta temporada do seriado Glee

\begin{tabular}{|l|l|}
\hline Legenda original: & Legenda traduzida: \\
00:10:21,401 $\rightarrow$ 00:10:23,899 & 00:10:21,401 $\rightarrow$ 00:10:23,899 \\
You want to get to Broadway, & Se quer chegar a Broadway, \\
you have to pay your dues. & tem que pagar suas dívidas. \\
\hline
\end{tabular}

Fonte: Elaborado pelas autoras. 
Quadro 2 - Trecho retirado do terceiro episódio da quinta temporada do seriado Glee

\begin{tabular}{|l|l|}
\hline Legenda original: & Legenda traduzida: \\
00:18:37,896 $\rightarrow$ 00:18:40,715 & $00: 18: 37,896 \rightarrow 00: 18: 40,715$ \\
-You get the hell out of my office! & -Saia do meu escritório! \\
-How about you make me get & -Que tal você me fazer sair? \\
the hell out of your office? & \\
\hline
\end{tabular}

Fonte: Elaborado pelas autoras.

No Quadro 1, a personagem Santana fala com Rachel que ela precisa batalhar para chegar à Broadway. A tradução feita foi a literal, o tradutor traduziu cada elemento da EI, mantendo as estruturas do nível sintático, porém não se levou em consideração o nível pragmático, referente ao uso da EI, que neste caso seria que a personagem teria que fazer por onde conseguir, ou seja, correr atrás do sonho dela e não pagar as dívidas.

No Quadro 2 a professora Sue tenta expulsar Santana do seu escritório. No português do Brasil a tradução de "get the hell out of" não ficaria adequada se fosse feita literalmente, por isso a tradução escolhida como "saia" e "sair" se adequou ao contexto de uso, uma vez que foi levado em consideração o aspecto semântico e pragmático, mantendo-se o sentido da frase e escolhendo uma frase que está de acordo com o que os falantes do português do Brasil usam.

A seguir, apresentaremos a metodologia utilizada para alcançar os objetivos do capítulo. Para tanto, apresentaremos o seriado, discutiremos o corpus analisado, além de descrever as categorias de análise do corpus e as ferramentas de auxílio para a análise. 


\section{Sistematizando um estudo sobre legendas}

O objetivo aqui é expor a metodologia utilizada para atingir os objetivos deste capítulo.

Conhecendo o seriado Glee: os três episódios escolhidos

Glee é uma série de televisão norte-americana exibida pelo canal FOX e produzida por Ryan Murphy, Ian Brennan e Brad Falchuk. Ela teve seis temporadas, sendo a primeira iniciada no dia 19 de maio de 2009 e a última encerrada no dia 20 de março de 2015. Ao todo foram 121 episódios, da primeira à quarta temporada cada uma teve 22 episódios, a quinta temporada teve 20 episódios e a última, 13 episódios. A série é sobre jovens ambiciosos e talentosos que entram para o Clube Glee Novas Direções (o coral da escola McKinley) que é coordenado pelo professor Will Schuester (personagem de Matthew Morrison) e perseguido pela professora Sue Silvester (que odeia todos do coral). No coral, os alunos são bem diferentes uns dos outros, desde os mais populares até os mais perdedores da escola. Essa diferença é o que chama atenção do público, pois se identificam com os personagens, e mesmo os que são considerados perdedores, mostram que são capazes de vencer.

No primeiro episódio selecionado, houve 5.060 .000 espectadores, no segundo, 4.420.000 de espectadores e no terceiro episódio houve 7.390 .000 espectadores $^{7}$. As legendas produzidas pela equipe Griots Team mais aces-

7 Verificamos esse dado no site: <http://www. adorocinema.com/series/serie-4114/audiencias/\#22500_on 
sadas da quinta temporada de Glee também foram as dos três primeiros episódios, com uma média de mais de 14 $\mathrm{mil}^{8}$. Esse fato, provavelmente, ocorre porque um dos principais atores (Cory Monteith) da série morreu antes da quinta temporada ir ao ar e os fãs e público em geral quiseram ver como seria o desfecho do personagem Finn Hudson em Glee.

O primeiro episódio é intitulado, Love, love, love, e é o primeiro dos dois episódios que fizeram um tributo a banda The Beatles. O segundo episódio da quinta temporada da série foi o Tina in the Sky with Diamondss. O último episódio escolhido e terceiro da quinta temporada foi um tributo ao personagem Finn Hudson e a Cory Monteith que o interpretava e foi intitulado "The Quarterback".

\section{O corpus da análise}

Olohan (2006) define corpus como:

Uma coleção de textos, selecionados e compilados de acordo com critérios específicos. Os textos são armazenados em formato eletrônico, como em arquivos de computador, para que vários tipos de ferramentas de

_20024>. Acesso em: 16 set. 2015. O número de espectadores foi contado apenas na primeira exibição de cada episódio.

8 Os números exatos podem ser visualizados no site que publicou as legendas: <http://legendas.tv/busca/Glee/ 30742>. Acesso em: 16 set. 2015. 
corpus, como um software, possam ser utilizados para realizar as análi$\operatorname{ses}^{9}$ (OLOHAN, 2006, p. 1, tradução nossa).

Para coletarmos o corpus, assistimos uma vez a cada um dos três episódios do seriado sem legenda, assistimos três vezes a cada um dos episódios com legenda em inglês, assistimos duas vezes a cada um dos episódios com legenda em inglês e em português (com o auxílio do software Subtitle Workshop), e assistimos três vezes aos dois primeiros episódios e quatro vezes ao terceiro até conseguirmos encontrar todas as EI. A medida em que alguma EI surgia, parávamos o episódio para anotações. Decidimos não utilizar as EI que estavam nas letras das músicas cantadas pelos personagens, porque teríamos que explorar outro gênero (música) e isso fugiria do objetivo de verificarmos as EI que foram escritas no roteiro para cada um dos personagens.

Utilizamos os termos forma (type) e ocorrência (token) da Linguística de Corpus para contabilizarmos o número de EI em língua inglesa do corpus deste capítulo. A forma corresponde a cada item, sem levar em consideração a repetição de cada um, obtivemos um total de 51 formas, ou seja, 51 EI distintas. A ocorrência corresponde ao número total de itens, incluindo as repetições deles, obtivemos um total de 59 ocorrências, sendo cinco EI

9 A corpus is a collection of texts, selected and compiled according to specific criteria. The texts are held in eletronic format, i.e. as computer files, so that various kinds of corpus tools, i.e. software, can be used to carry out analysis on them (OLOHAN, 2006, p.01). 
repetidas nos episódios. Para facilitar essa contagem, criamos um quadro no Microsoft Word com as EI em ordem alfabética e as EI que se repetem foram destacadas.

Após a seleção das EI, elas foram inseridas em quadros feitos no Microsoft Word, separadas inicialmente por episódios. A primeira coluna dos quadros possui as linhas das legendas em inglês (em negrito, itálico e sublinhado), além dos nomes dos personagens que falaram e a segunda coluna possui as linhas das legendas traduzidas para o português do Brasil (em negrito e sublinhado). Como se pode observar no Quadro 3 a seguir:

Quadro 3 - Trechos retirados do segundo episódio da quinta temporada do seriado Glee

\begin{tabular}{|c|c|}
\hline Legenda original: & Legenda traduzida: \\
\hline SR. SCHUE & \\
\hline 00:00:39,151 $\rightarrow$ 00:00:41,822 & 00:00:39,151 $\rightarrow$ 00:00:41,822 \\
\hline where they literally and figuratively & fazendo que eles deixassem \\
\hline let their hair down. & os cabelos crescerem. \\
\hline TINA & \\
\hline 00:02:07,514 $\rightarrow$ 00:02:09,863 & 00:02:07,514 $\rightarrow$ 00:02:09,863 \\
\hline I need to maximize my odds & Preciso ter todas as chances \\
\hline of taking the crown, & de ganhar, \\
\hline TINA & \\
\hline 00:02:12,122 $\rightarrow$ 00:02:14,917 & 00:02:12,122 $\rightarrow$ 00:02:14,917 \\
\hline And I am going for it. & Vou batalhar por isso. \\
\hline
\end{tabular}

Fonte: Elaborado pelas autoras. 
Essa divisão feita caracteriza este corpus como paralelo e Zanettin (2000, p. 106) descreve corpus paralelo como um conjunto de traduções em uma língua e a tradução correspondente em outra língua. $\mathrm{O}$ autor afirma que o corpus paralelo pode ser utilizado para apresentar o que os tradutores fizeram, e a partir dessa comparação entre o texto original e o texto traduzido é que faremos as análises, observando quais estratégias de tradução foram escolhidas e as implicações dessas escolhas.

Para não perdermos o contexto de cada EI, contamos com o auxílio do software Bandicam para selecionarmos as cenas em que as EI estavam e as capturamos em vídeos no formato $A V I^{10}$ com legendas em português.

\section{Descrição das categorias escolhidas para a divisão do corpus}

Com a contribuição das estratégias para a tradução de EI que Baker (1992) apresenta e que já mencionamos no tópico anterior, decidimos separar o corpus em quatro categorias: 1) tradução literal de EI, perdendo-se o sentido dela; 2) tradução de uma EI por outra EI com o mesmo efeito; 3) tradução de uma EI por meio de paráfrase; e, 4) omissão da EI.

Para isso, outros quadros foram criados no Microsoft Word, um para cada categoria. Na primeira coluna apresentamos a legenda em inglês com as EI destacadas em negrito e sublinhadas; na segunda coluna, apresentamos a legenda em português traduzida pela equipe de

10 O formato AVI é um dos mais populares e é reconhecido pela maioria dos leitores de vídeos. 
legendagem de fãs com as EI destacadas em negrito e sublinhadas; na terceira coluna, tem-se a definição da EI; na quarta coluna, apresentamos a estratégia de tradução utilizada de acordo com as que Chesterman (1997) propõe; e, na última coluna, indicamos de qual episódio o trecho foi retirado.

Ferramentas de auxílio para análise

A seguir, descreveremos os dois softwares que foram usados como ferramentas para as análises de dados, o Subtitle Workshop e o Bandicam, respectivamente.

\section{Subtitle Workshop}

O Subtitle Workshop ${ }^{11}$ é um software gratuito para criar, editar e converter arquivos de legendas com base em texto. Utilizamos a versão 2.52 do software para verificar os aspectos técnicos da legendagem e foi a mesma versão utilizada pelos tradutores de legendas da equipe de legendagem de fãs Griots Team. Cursos de legendagem também o utilizam, como é o caso da GTC Treinamento ${ }^{12}$.

Para configurá-lo, seguimos os passos:

1. Abrir o Subtitle Workshop e apertar ALT + I;

2. No item "Guia Geral" deixar somente estas opções marcadas:

11 Software disponível gratuitamente para download em: <http:/ / subworkshop.sourceforge.net/ $>$.

12 Informações sobre o curso de legendagem disponíveis em: $<$ http://gtctreinamento.com.br/>. 
a. Marcar Erros na Lista do Formato Principal; b. Negrito; c. Marcar erros ao abrir a legenda.(Conforme a Figura 1)

3. No item "Guia Avançado" configurar:

a. Duração muito longa: 5000 / b. Duração muito curta: 1400 / c. Linha muito longa: 33 d. CPS superior ou igual a: 20,01 / e. Espaço após caractere: (Conforme a Figura 2)

4. No item "Verificar Por" deixar marcado conforme a Figura 3.

5. Arrastar o vídeo e as legendas para o software.

6. Utilizar os atalhos da Figura 4 para facilitar a manuseio do software.

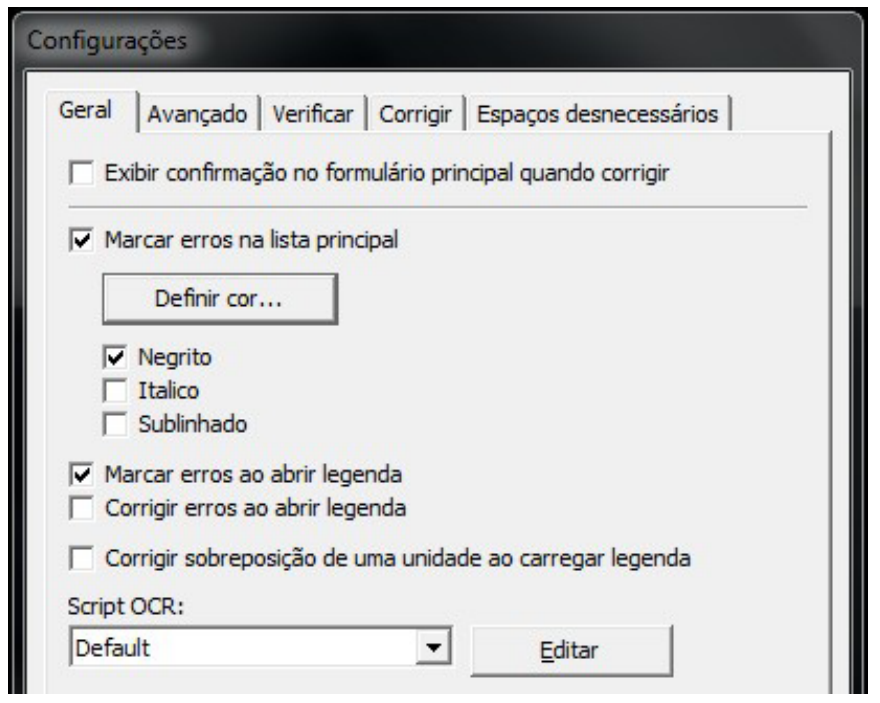

Figura 1 - Segundo passo das configurações do Subtitle Workshop Fonte: Subtitle Workshop. 


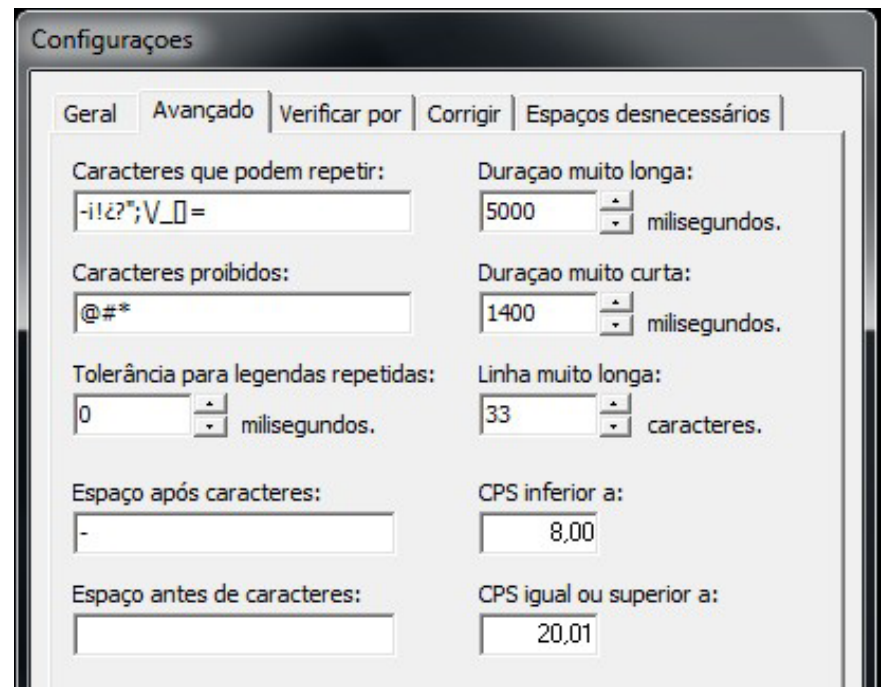

Figura 2 - Terceiro passo das configurações do Subtitle Workshop Fonte: Subtitle Workshop.

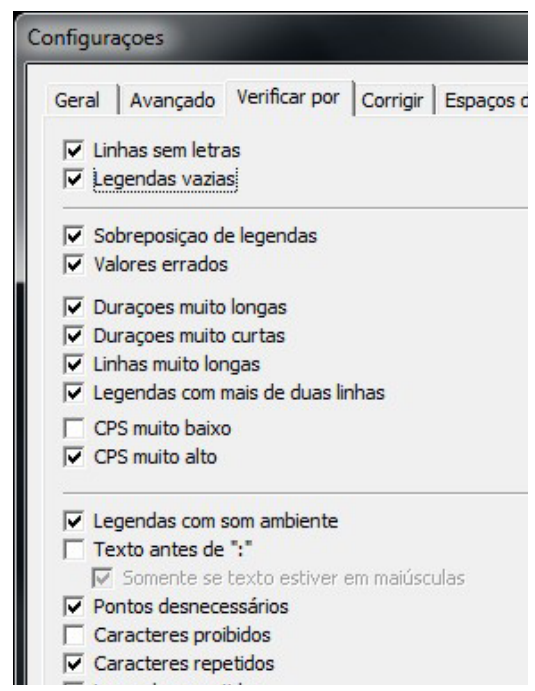

Figura 3 - Quarto passo das configurações Subtitle Workshop

Fonte: Subtitle Workshop. 


\begin{tabular}{|c|c|c|}
\hline & ATALHO & $A C \not \subset O$ \\
\hline \multirow{5}{*}{ TEMPOS } & $A L T+C$ & Define o tempo de inicio de exibição da legenda \\
\hline & $A L T+V$ & Define o tempo de término de exibiçăo da legenda \\
\hline & CTRL+SHIFT+E & Estende o tempo de duraçâo da legenda até o ínicio da outra \\
\hline & $\mathrm{CTRL}+\mathrm{SHIFT}+\mathrm{N}$ & Muda a legenda +100 milissegundos \\
\hline & $\mathrm{CTRL}+\mathrm{SHIFT}+\mathrm{H}$ & Muda a legenda - 100 milissegundos \\
\hline \multirow{4}{*}{ TEXTOS } & INSERT & Inserir nova legenda abaixo da atual \\
\hline & SHIFT+INSERT & Inserir nova legenda antes da atual \\
\hline & $C T R L+K$ & Junta as legendas selecionadas, preservando os tempos \\
\hline & $C T R L+S H I F T+D$ & Divide os textos das legendas e seus tempos \\
\hline \multirow{5}{*}{ VIDEO } & CTRL+ESPACCO & Pausa/Continua reprodução \\
\hline & $\mathrm{ALT}+\longrightarrow$ & Avança 1 segundo, se pressionado \\
\hline & $\mathrm{ALT}+\longleftarrow$ & Retrocede 1 segundo, se pressionado \\
\hline & $\mathrm{CTRL}+\longrightarrow$ & Avança 5 segundos, se pressionado \\
\hline & $\mathrm{CTRL}+\longleftarrow$ & Retrocede 5 segundos, se pressionado \\
\hline \multirow{4}{*}{ REVISĀO } & CTRL+1 & Abre janela de erros na legenda \\
\hline & $C T R L+S H I F T+Y$ & Expandir/Reduzir tempos \\
\hline & $C T R L+L$ & Determina valores mínimos e máximos de duração \\
\hline & $C T R L+D$ & Adianta/retrocede legendas (usado em resyncs) \\
\hline
\end{tabular}

Figura 4 - Sexto passo das configurações do Subtitle Workshop

Fonte: Elaborado pelas autoras.

Após os ajustes feitos nas configurações do software, deu-se início às análises dos aspectos técnicos das legendas escolhidas. O Subtitle Workshop possibilitou também que as pesquisadoras pudessem assistir aos episódios com a legenda em inglês, em seguida com a legenda em português e por fim, com as duas legendas, em português e em inglês ao mesmo tempo.

Feita a descrição do software utilizado para as questões das legendas, descreveremos, a seguir, o software que foi usado para a captura das cenas do seriado.

\section{Bandicam}

Utilizamos o software Bandicam para capturar vídeos dos episódios selecionados para que as EI não ficassem 
descontextualizadas. Este software tem uma versão gratuita e uma paga, utilizamos a gratuita que supriu as nossas necessidades neste capítulo, já que podemos capturar até dez minutos de vídeo por cada arquivo. Além de capturar vídeos, o software também captura imagens, mas não utilizamos esse recurso.

Para configurar o software, seguimos os passos:

1. Escolher na aba GERAL no item Opções, a pasta de saída para armazenar os vídeos. Escolhemos salvar na pasta de documentos com uma subpasta com o nome do software (Conforme Figura 5);

2. Clicar em VÍDEO e ativar Gravar/Parar atalho, escolhemos o atalho como a letra $\mathbf{A}$, mas qualquer outra tecla pode ser escolhida. (Conforme Figura 6);

3. Escolhemos o formato de vídeo AVI por ser facilmente reconhecido em programas de exibição de vídeo. Para as configurações técnicas do vídeo escolhemos: Xvid (VBR), Full Size, 3000fps, 80q (configurações já vindas no software). E para as configurações do áudio escolhemos: MPEG-1 L2, 48,0KHz, stereo, 192kbps (configurações já vindas no software). (Conforme Figura 6);

4. Após as configurações ajustadas, abrimos o vídeo com a legenda em português e fomos selecionando as cenas uma a uma (as que continham EI nos diálogos) e em seguida, verificamos se os vídeos estavam adequados ou se ficaram com alguma falha (foi capturar os vídeos mais de uma vez cada um, pois as imagens às vezes ficavam com o áudio atrasado em relação com as imagens). 
No processo de capturar as partes dos episódios que continham as EI, seguimos o passo a passo descrito acima e obtivemos um total de 32 cenas gravadas através deste software. A importância de se ter essas cenas se dá pela necessidade de se analisar o contexto em que as EI estão inseridas, uma vez que, ter apenas as EI não é suficiente para se fazer uma análise, pois as EI ganham sentido de acordo com a situação de uso.

Após termos apontado os caminhos metodológicos percorridos; a seguir apresentaremos a análise dos dados.

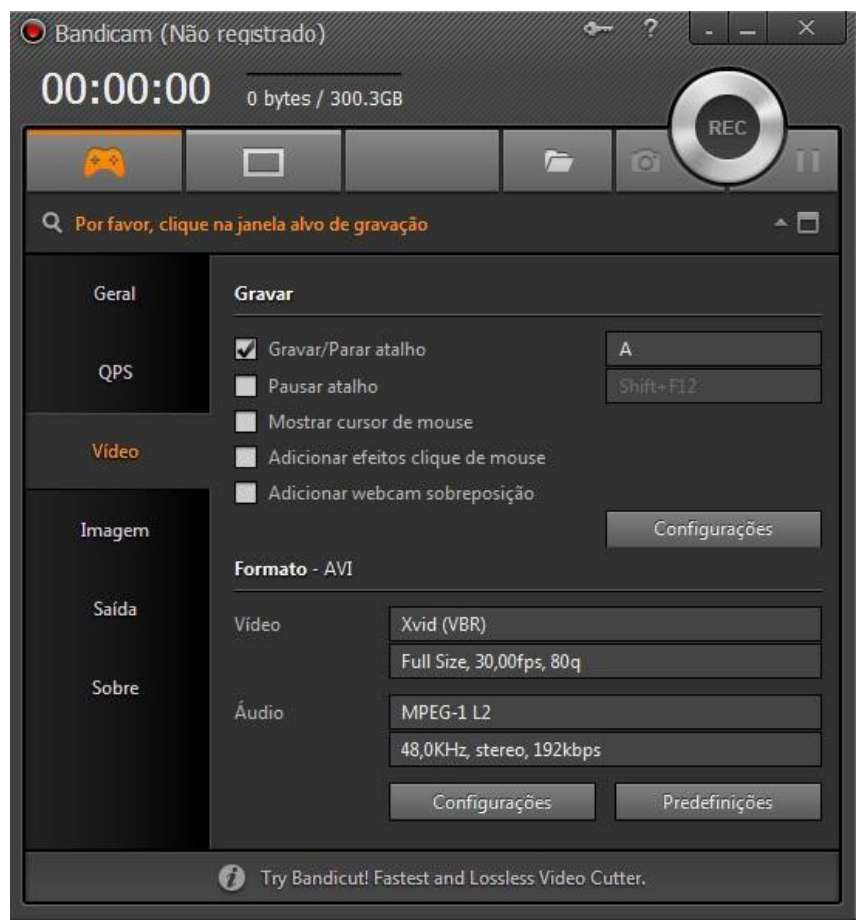

Figura 5 - Configuração do Bandicam -Geral Fonte:Bandicam. 


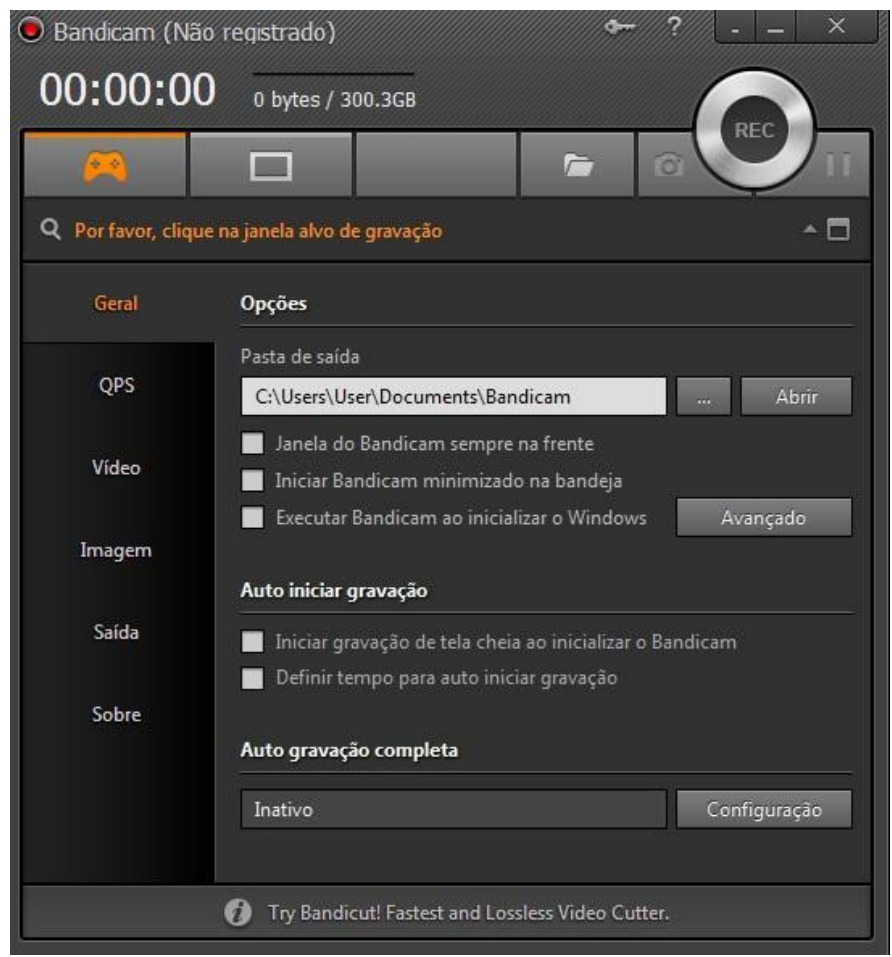

Figura 6 - Configuração do Bandicam-Video

Fonte:Bandicam.

\section{Olhar analítico sobre legendas: números e representações}

A seguir apresentamos a análise quantitativa dos dados, observando as estratégias de tradução utilizadas na tradução das EI nas legendas. 
Quantificações das El distribuídas em categorias

As EI foram organizadas segundo as categorias como apresentado abaixo:

Categoria 1:Tradução literal de EI, perdendo-se o sentido dela (04 ocorrências)

Episódio I $\rightarrow$ a) to pay your dues - pagar suas dívidas.

Episódio II $\rightarrow$ a) let their hair down - deixassem os cabelos crescerem; b) get that reference - peguei a referência; c) that ship has sailed - esse navio já partiu.

\section{Categoria 2: Tradução de uma EI por outra com o mesmo efeito (24 ocorrências)}

Episódio I $\rightarrow$ a)on the black side - meio por fora; b) on the down-low - -s escondidas; c) hands are tied - mãos estão atadas; d) at a turning point - em tempo de mudança; e) put the hells out - dê o fora; f) in one fell swoop - num piscar de olhos; g) keep it hush-hush - manter em segredo; h) found your calling - nasceu para fazer isso.

Episódio II $\rightarrow$ a) I am going for it - vou batalhar por isso; b) to tie yourself down - apertar o cinto; c) a rough ride uma viagem difícil; d) I do not give a flying fart - não dou a mínima; e) get the hell out of - dê o fora; f) hot off the presses - acabou de sair de forno; g) Hot off the presses? - Acabou de sair do forno?; h) wet your bed - você molhava sua cama; i) don't give a fart - não dá a mínima.

Episódio III $\rightarrow$ a) to move on - seguir em frente; b) making a self-serving spectacle - fazendo um espetáculo; c) the dark side - lado negro; d) chickened out - amarelei; e) treat me with kid gloves - sentir pena de mim; f) kick the crap out of - chutar a bunda; g) leave the nest - deixando o ninho. 


\section{Categoria 3: Tradução de uma EI por meio de pará- frase (30 ocorrências)}

Episódio I $\rightarrow$ a) break it down - explicar; b) you cheated on me -você me traiu; c) out of the picture - fora; d) cheat on you - trairia você; e) give it a try - tentar; f) put something together - fiz uma coisinha; g)in a pinch - em apuros; h) had each other's backs - se apoiaram; i) to step in - agirmos; j) she's falling apart - ela está desmoronando.

Episódio II $\rightarrow$ a) maximize my odds - ter todas as chances; b) on the verge of crying about - estejam chorando; c) freak me out - me apavoram; d) I would watch your tone - eu manteria o tom; e) making out - beijando; f) all hell broke loose - tudo desabou; g) hang out - ficar comigo; h) get the hell out of - sair; i) go after - acabar; j) go after - vá atrás; k) can't help não poderão evitar.

Episódio III $\rightarrow$ a) keep that out - escondo isso; b) to get us through - para passarmos; c) hard times - dificuldades; d) bummed out - chateado; e) get the hell out of - saia; f) get the hell out of - sair; g) can't take it - não consigo aguentar; h) rush me out of the door - me apressar para eu sair daqui; i) tripping me out - me incomoda.

\section{Categoria 4: Omissão da EI (01 ocorrência)}

Episódio II $\rightarrow$ a) and the Cheerios do not give a flying fart - e as Cheerios também não.

Em suma, podemos verificar que: na categoria 1 obtivemos uma ocorrência no $1^{\circ}$ episódio, três no $2^{\circ}$ episódio e nenhuma no $3^{\circ}$ episódio; na categoria 2 encontramos oito ocorrências no $1^{\circ}$ episódio, nove no $2^{\circ}$ episódio e sete no $3^{\circ}$ episódio; na categoria 3 observamos dez ocorrências no $1^{\circ}$ episódio, onze no $2^{\circ}$ episódio e nove no $3^{\circ}$ episódio; e, 
por fim, na categoria 4 há uma ocorrência apenas no $2^{\circ}$ episódio. Para que fiquem mais claros esses dados, podemos visualizá-los no gráfico 1 .

Chegamos a um total de 59 ocorrências de EI nas três legendas selecionadas, sendo 19 EI encontradas no primeiro episódio, 24 no segundo e 16 no terceiro episódio. Verificou-se que das 59 ocorrências: 4 EI foram traduzidas literalmente, perdendo-se o sentido idiomático; 24 EI foram traduzidas por outras EI com o mesmo efeito; 30 EI foram parafraseadas; e, uma EI foi omitida. Podemos ver esses dados em porcentagem no Gráfico 2.

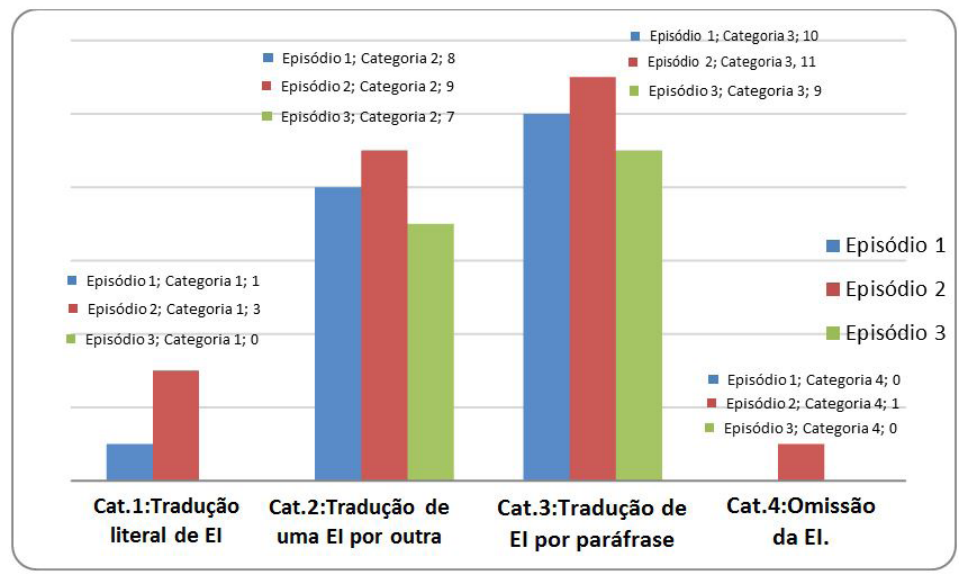

Gráfico 1 - Número de EI encontradas em cada episódio, dividido pelas quatro categorias

Fonte: Elaborado pelas autoras. 


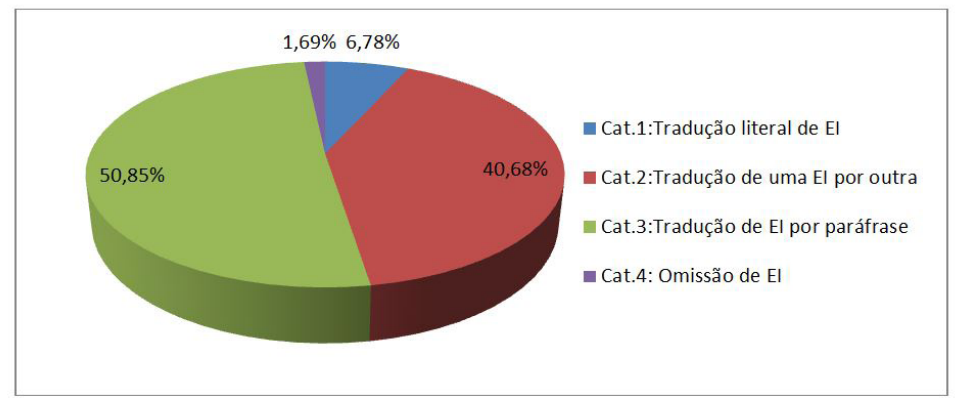

Gráfico 2 - Porcentagem das categorias

Fonte: Elaborado pelas autoras.

Com isso, constatamos que a escolha mais usada pelos tradutores foi a de parafrasear as EI (50,85\%), em seguida foi escolhido traduzir as EI por EI com o mesmo efeito da EI original (40,68\%). O sentido das EI foram perdidos em 6,78\% delas, uma vez que os tradutores usaram tradução literal, de modo que as traduções não estavam adequadas em relação ao texto original e nem fizeram sentido para a cultura brasileira. E por fim, a omissão foi apenas utilizada em uma EI (1,69\%).

Inferimos, a partir desses dados, que os tradutores conseguiram, de forma geral, traduzir as EI dos episódios escolhidos. Porém, em quatro casos a tradução literal não fez sentido com relação ao contexto, isso pode ter ocorrido porque os tradutores não conheciam o sentido que elas tinham no contexto norte-americano. $\mathrm{O}$ alto índice de ocorrências de paráfrases nos mostra que, mesmo que os tradutores não conhecessem uma EI que tivesse o mesmo efeito para o contexto brasileiro, não deixaram de encontrar um meio para transmitir a mensagem que se adequava à nossa cultura. Os 40,68\% de EI que foram traduzidas por 
outras EI nos dá a impressão de que os tradutores além de compreenderem a língua e a cultura brasileira, conhecem também a língua e a cultura norte-americana, uma vez que foram utilizadas EI que tinham o mesmo efeito para os dois lugares. E a questão de apenas uma ocorrência de omissão pode ser entendida como um ponto positivo dos tradutores, que podem ter optado por traduzirem as demais EI por julgarem serem importantes para a compreensão da mensagem e o caso da omissão foi utilizada apenas para evitar uma repetição, pois a mesma EI tinha sido utilizada anteriormente.

Analisando as estratégias utilizadas pelos tradutores, segundo a classificação de Chesterman (1997) apresentada no tópico 1.2.2 (estratégias de tradução em nível sintático, semântico e pragmático), percebemos que mais de uma estratégia pode ser usada para cada tradução de EI. Das 59 ocorrências de EI temos que: a Tradução Literal (G1) foi utilizada em 7 EI; o Deslocamento de unidade (G4) foi empregado em 41 EI; a Mudança estrutural da frase (G5) foi usada em 56 EI; a Mudança de coesão (G8) foi aplicada em uma EI; uma EI foi traduzida por meio da Sinonímia (S1); 6 EI foram traduzidas recorrendo-se à Mudança de ênfase (S7); 47 EI foi traduzidas através de Paráfrase (S8); 5 EI foram traduzidas usando Outras Mudanças Semânticas (S10), nestes casos, a mudança de sentido; o Filtro cultural (Pr1) foi aplicado em 3 EI; a Mudança de Explicitação (Pr2) foi utilizada em uma EI; e, a Mudança de Informação (Pr3) foi empregada em uma EI, neste caso a omissão da EI. Pode-se verificar esses números no Gráfico 3. 


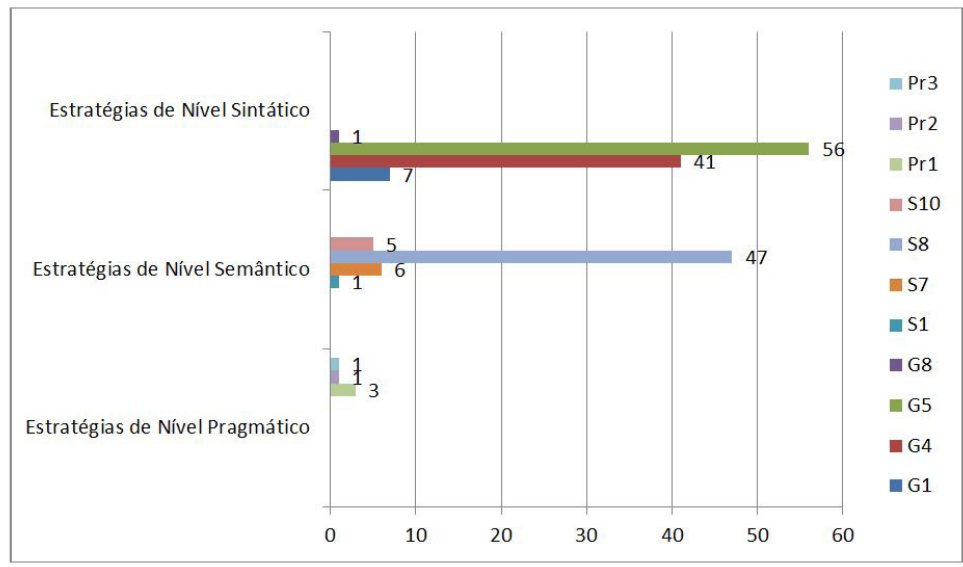

Gráfico 3 - Quantidade de cada estratégia de tradução (CHESTERMAN, 1997) utilizada nas traduções das EI separadas pelos níveis: sintático, semântico e pragmático

Fonte: Elaborado pela autora.

Ou seja, das 30 estratégias propostas por Chesterman (1997), encontramos 11 utilizadas nas traduções das EI, sendo quatro delas estratégias de nível sintático, quatro de nível semântico e três de nível pragmático.

Podemos observar que o maior número de uso foi das estratégias de nível sintático, ou seja, os tradutores optaram por manipular mais as formas. Em seguida, também em grande número, ficou o uso de estratégias semânticas que são aquelas que manipulam o significado. Por último, as estratégias de nível pragmático praticamente não foram utilizadas, o que podemos deduzir que não houve uma maior mudança do texto de partida.

Das 59 ocorrências, obtivemos 51 EI distintas, uma vez que cinco EI se repetiram ("cheat on", "get the hell out of", "give a (flying) fart", "hot off the presses" e "go after"). Destas 
EI repetidas, "cheat on" (do episódio 1) foi encontrada duas vezes e foi traduzida por meio de paráfrase (Categoria 3) pelo verbo "trair", mudando apenas o tempo verbal de cada uma; "get the hell out of" foi encontrada quatro vezes (duas vezes no episódio 2 e duas vezes no episódio 3 ) e foi traduzida por meio de paráfrase (Categoria 3) três vezes pelo verbo "sair", mudando apenas a conjugação verbal e uma vez traduzida por outra EI (Categoria 2), "dê o fora"; "give a (flying) fart" foi encontrada três vezes (no episódio 2), foi traduzida duas vezes por outra EI (Categoria 2), "não dar a mínima", mudando a pessoa e uma vez a EI foi omitida(Categoria 4). Podemos melhor observar no Quadro a seguir:

Quadro 4 - EI que se repetiram nos episódios selecionados

\begin{tabular}{|l|l|l|}
\hline EI em inglês & EI traduzida & Episódio e Categoria \\
\hline $\begin{array}{l}\text { you cheated on me } \\
\text { cheat on you }\end{array}$ & $\begin{array}{l}\text { você me traiu } \\
\text { trairia você }\end{array}$ & $\begin{array}{l}\text { Episódio 1/Categoria 3 } \\
\text { Episódio 1/Categoria 3 }\end{array}$ \\
\hline $\begin{array}{l}\text { get the hell out of } \\
\text { get the hell out of } \\
\text { get the hell out of } \\
\text { get the hell out of }\end{array}$ & $\begin{array}{l}\text { dê o fora } \\
\text { sair } \\
\text { saia } \\
\text { sair }\end{array}$ & $\begin{array}{l}\text { Episódio 2/Categoria 2 } \\
\text { Episódio 2/Categoria 3 } \\
\text { Episódio 3/Categoria 3 } \\
\text { Episódio 3/Categoria 3 }\end{array}$ \\
\hline $\begin{array}{l}\text { I do not give a flying } \\
\text { fand the Cheerios do do } \\
\text { not give a flying fart } \\
\text { don't give a fart }\end{array}$ & $\begin{array}{l}\text { não dou a mínima } \\
\text { não Cheerios também } \\
\text { não dá a mínima }\end{array}$ & Episódio 2/Categoria 2 \\
\hline $\begin{array}{l}\text { hot off the presses } \\
\text { Eot off the presses? }\end{array}$ & $\begin{array}{l}\text { acabou de sair de forno 2/Categoria 4 } \\
\text { forno? de sair do }\end{array}$ & Episódio 2/Categoria 2 \\
\hline $\begin{array}{l}\text { go after } \\
\text { go after }\end{array}$ & $\begin{array}{l}\text { Ecabódio 2/Categoria 2 } \\
\text { vá atrás }\end{array}$ & Episódio 2/Categoria 2 \\
\hline
\end{tabular}

Fonte: Elaborado pela autora. 
Observamos, ainda, que alguns personagens usam mais EI do que outros e esse uso acaba se tornando uma marca do personagem. A professora Sue é a que mais utiliza EI, ela usou 14; em seguida vem Blaine e Santana com 7 EI cada um; depois a líder de torcida Bree com 5 EI; o professor Schue utilizou 4 EI; Rachel e Kurt com 3 EI cada um; Kity, Puck, Tina, Dani e os policiais utilizaram 2 EI cada um; e por fim, Jake, Unique, Sam, Mercedes, o pai de Kurt, e Artie usaram, cada um, uma EI.

\section{Considerações finais}

O objetivo deste capítulo foi analisar a tradução de EI em legendas de três episódios do seriado Glee, da língua inglesa norte-americana para a língua portuguesa do Brasil, produzida por uma equipe de tradutores de legendas de fãs, a ser trabalhado a partir da identificação, categorização e quantificação das estratégias tradutórias utilizadas para a tradução de EI nas legendas. O objetivo foi alcançado por meio de análise quantitativa.

$\mathrm{Na}$ análise quantitativa verificamos que os tradutores conseguiram traduzir, de maneira geral, as EI dos três episódios escolhidos. Entretanto o uso da tradução literal em quatro EI não fez sentido com relação ao contexto norte-americano. A questão de apenas uma ocorrência de omissão foi um destaque positivo dos tradutores, que optaram por evitar uma repetição, já que a mesma EI foi usada antes.

A maior parte das traduções das EI foram feitas por meio de paráfrase ou por outras EI, observamos, com isso, que os tradutores além de compreenderem a língua e a cultura brasileira, são conhecedores também da língua e 
da cultura norte-americana, uma vez que foram utilizadas EI e paráfrases que tinham o mesmo efeito para as duas culturas.

A série tem ainda o seu lado da censura, uma vez que se pensa no público alvo, de jovens e a linguagem utilizada se adequa a eles, assim como também foi pensado por quem traduziu as legendas. Portanto, vemos que o seriado transmitiu essa mesma mensagem nas duas culturas aqui analisadas, o que nos leva a crer que quem a traduziu para o Brasil, através da legendagem, foi capaz de adaptar ao contexto cultural brasileiro.

Percebemos também a importância que o tradutor de legendas assume, tendo uma função social de caráter inclusivo para aquelas pessoas que, sem eles, não teriam acesso a filmes e seriados, pelos mais diversos motivos, como o lugar que moram, a falta de conhecimento da língua estrangeira, as condições financeiras, entre outros.

Sabendo da fundamental importância dos tradutores de legenda, acreditamos que esse estudo possa servir de inspiração para que sejam incluídas, em cursos de graduação de Letras ou Tradução, disciplinas sobre legendagem, já que o que se tem nos dias atuais são apenas cursos de pequena duração sobre legendagem. Inserindo disciplinas de legendagem, a formação de tradutores de legendas vai além de treinamentos com foco em aspectos da legendagem, os alunos aprenderiam também as questões teóricas da TAV que em cursos técnicos não são apresentadas.

Fazendo isso, haveria uma formação mais completa para tradutores, pois nas disciplinas de tradução para legendagem seriam desenvolvidas habilidades como: o poder de sintetizar textos, a análise textual e o domínio 
de ferramentas utilizadas na legendagem (MARTINEZ, 2007).

Por fim, a inclusão de disciplinas sobre legendagem nas universidades faria com que a profissão dos tradutores de legendas fosse mais valorizada, uma vez que a qualidade das legendas aumentaria por meio de estudos teóricos e técnicos acerca da legendagem.

\section{REFERÊNCIAS}

ALVAREZ, Maria Luisa Ortiz. Traduzir uma expressão idiomática não é quebrar galho, é descascar um abacaxi. In: SANTOS, C.A.B.; BESSA, C. R.; HATJE-FAGGION, V.; SOUSA, G. H. P. Tradução e Cultura. Rio de Janeiro: 7 Letras, 2011.

ARAÚJO, Vera Lúcia Santiago. O processo de legendagem no Brasil. Ceará: Universidade Estadual do Ceará, 2004.

BAKER, M. In Other Words. A Coursebook on Translation. Routledge, 1992.

CARVALHO, Carolina Alfaro de. A tradução para legendas: dos polissistemas à singularidade do tradutor. Dissertação de Mestrado. Rio de Janeiro: PUC-Rio, Departamento de Letras, 2005.

CHESTERMAN, Andrew. Memes of Translation: the spread ideias in translation theory. Amsterdam/ Philadelphia: John Benjamins Publishing Company, 1997. 
CINTAZ, Jorge Diaz; SÁNCHEZ, Pablo Muños. Fansubs: Audiovisual Translation in an Amateur Environment. In: Journal of Specialised Translation, Issue 06, p.3752, 2006. Disponível em: <http://www.jostrans.org/ issue06/art_diaz_munoz.pdf $>$.

CINTAZ, Jorge Diaz; ANDERMAN, Gunilla. Audiovisual Translation: Language Transfer on Screen. Palgrave MacMillan: 2009.

CINTAZ, Jorge Dias; REMAEL, Aline. Audiovisual Translation: Subtitling. UK, 2010.

FRANCO, Eliana P.C.; ARAÚJO, Vera Santiago. Questões Terminológico-Conceituais no Campo da Tradução Audiovisual (TAV). Tradução em Revista 11, 2011.

GOROVITZ, Sabine. Os labirintos da tradução: a legendagem e a construção do imaginário. Brasília: Editora UnB, 2006.

LINDE; KAY. The semiotics of subtitling.UK, 2009.

RIDD, M. D. Legendagem: corda bamba entre oral e escrito. In: ANAIS do I Encontro Nacional de Interação em Linguagem Verbal e Não-Verbal. UnB, 1995.

SILVA, Thaís Francis. Pela lente da legenda: um estudo de caso na recepção audiovisual. Brasília, 2009.

TAGNIN, Stella Esther Ortweiler. Expressões idiomáticas e convencionais. São Paulo: Ed. Ática, 1989. 
TEIXEIRA, E. As três metodologias: acadêmica, da ciência e da pesquisa. Petrópolis/RJ: Vozes, 2007.

VENUTI, L. The Scandals of translation: towards an ethics of difference. London \& New York: Routledge, 1999.

WILLIAMS, J.; CHESTERMAN, A. The Map: A beginner's guide to doing research in translation studies. St. Jerome Publishing, 2002. 